\title{
Effects of agrochemicals, ultra violet stabilisers and solar radiation on the radiometric properties of greenhouse films
}

\author{
Giuliano Vox, Evelia Schettini \\ Department of Agricultural and Environmental Science, University of Bari, Italy
}

\begin{abstract}
Agrochemicals, based on iron, sulphur and chlorine, generate by products that lead to a degradation of greenhouse films together with a decrease in their mechanical and physical properties. The degradation due to agrochemicals depends on their active principles, method and frequency of application, and greenhouse ventilation. The aim of the research was to evaluate how agrochemical contamination and solar radiation influence the radiometric properties of ethylene-vinyl acetate copolymer greenhouse films by means of laboratory and field tests. The films, manufactured on purpose with the addition of different light stabiliser systems, were exposed to natural outdoor weathering at the experimental farm of the University of Bari (Italy; $41^{\circ} 05^{\prime} \mathrm{N}$ ) in the period from 2006 to 2008. Each film was tested for two low tunnels: one low tunnel was sprayed from inside with the agrochemicals containing iron, chlorine and sulphur while the other one was not sprayed and served as control. Radiometric laboratory tests were carried out on the new films and on samples taken at the end of the trials. The experimental tests showed that both the natural weathering together with the agrochemicals did not modify significantly the radiometric properties of the films in the solar and in the photosynthetically
\end{abstract}

Correspondence: Giuliano Vox, Department of Agricultural and Environmental Science, University of Bari, Via Amendola 165/a, 70126 Bari, Italy. Tel. +39.080 .5443547 - Fax: +39.080 .5442977 .

E-mail: giuliano.vox@uniba.it

Key words: greenhouse film, iron, chlorine, sulphur, solar radiation, transmissivity.

Acknowledgements: the authors thank C. Anifantis and F. Ferrulli of the University of Bari for their cooperation in the field test.

Funding: the present work was carried out as part of the projects funded by P.A.T.I. S.p.A. (San Zenone degli Ezzelini, Treviso, Italy) during the period 2006-2008.

Contributions: the Authors contributed equally.

Received for publication: 10 July 2013.

Accepted for publication: 16 September 2013.

(C) Copyright G. Vox and E. Schettini, 2013

Licensee PAGEPress, Italy

Journal of Agricultural Engineering 2013; XLIV:e11

doi:10.4081/jae.2013.e11

This article is distributed under the terms of the Creative Commons Attribution Noncommercial License (by-nc 3.0) which permits any noncommercial use, distribution, and reproduction in any medium, provided the original author(s) and source are credited. active radiation wavelength range. Within six months of experimental field tests the variations in these radiometric characteristics were at most $10 \%$. Significant variations, up to $70 \%$ of the initial value, were recorded for the stabilised films in the long-wave infrared radiation wavelength range.

\section{Introduction}

The radiometric properties of covering greenhouse films influence both the energy balance of the greenhouse and the crop behaviour (Kittas and Baille, 1998; Papadakis et al., 2000; Vox et al., 2010). The microclimate of the protected volume modifies the growing conditions of the crop in comparison with the external climatic conditions according to the quantity and quality of the solar radiation passing through the covering. The stability over time of the radiometric properties of the film during the crop cultivation cycle is an important goal for growers.

Physical and mechanical properties decrease when the plastic film covering degrades in the field by discolouration, cracking of the surface, and stiffening. The average service life of plastic greenhouse films depends on parameters related both to the film itself and to the environment in which the film is used (Briassoulis, 2005; Briassoulis and Schettini, 2003; Desriac, 1991; Dilara and Briassoulis, 1998, 2000; Khan and Hamid, 1995; Martin-Closas et al., 2008; Ruiz et al., 2006), varying from 3-6 months, for one cultivation season, to a maximum of $3-4$ years in the Mediterranean area. The ultra violet (UV) radiation in the solar spectrum absorbed by the plastic films is one of the factors that have the biggest influence on the ageing and degradation process (Nijskens et al., 1990; Dilara and Briassoulis, 1998). The UV radiation, especially the UV-B and UV-A radiation that occurs in the wavelength range $280-400 \mathrm{~nm}$, causes photo-degradation by leading to bond cleavage and depolymerisation. Film lifespan in greenhouse applications can be extended by adding UV-stabilisers to mitigate degradation through the prevention of solar radiation absorption, as well as by minimising any subsequent radical oxidation reactions (Sanchez-Lopez et al., 1991). UV absorbers, hindered amine light stabilisers (HALS) and nickel quenchers are UV stabilisers. UV stabilisers absorb UV radiation and dissipate it into heat; HALS additives decompose radicals while nickel quenchers deactivate radicals, hampering the degradation process (Sanchez-Lopez et al., 1991).

Film lifespan is also affected by agrochemicals commonly sprayed by the growers due to a generation of by products that lead to a deterioration of the covering materials together with a variation in their mechanical and physical properties (Khan and Hamid, 1995; Espí et al; 2007; Rull and Marin, 2006). The degradation due to agrochemicals depends on their active principles, application method and frequency, ventilation and greenhouse structure (Dilara and Briassoulis, 2000).

The aim of the research is to study the effects of agrochemicals containing iron, chlorine and sulphur combined with solar radiation on the radiometric properties of ethylene-vinyl acetate copolymer (EVA) 
films used in greenhouse cultivation. The films were manufactured with the addition of different light stabiliser systems and were subjected to natural outdoor weathering in the experimental field. Radiometric tests were carried out in the laboratory on the new films and on samples taken at the end of the trials.

\section{Materials and methods}

The films, manufactured for the purpose by the P.A.T.I. S.p.A. company (San Zenone degli Ezzelini, Treviso, Italy), were tested during three different campaigns of trials in the period 2006-2008. All the films were $100 \mu \mathrm{m}$ thick and were made using the single layer blow-extrusion technology. Each film was identified by a code (Table 1): the letter (from $A$ to $E$ ) indicates the type of stabilisers used; the number (from 1 to 3 ), the year of the field trial. The percentages of the basic polymers and additives represent proprietary information and as such were not disclosed. UV stabilisers, i.e. triazine UV absorbers (Cytec Cyasorb®
1164), photoluminescent UV absorbers (VIBA UV Master 03081), methylated HALS (Cytec Cyasorb® UV-3529), and aminoether type hindered amine light stabiliser (NOR-HALS) (Ciba, now BASF, Tinuvin ${ }^{\circledR}$ NOR371), were added, alone or in combinations, to the basic polymers. EVA films, made with a copolymer including $5 \%$ vinyl acetate, were tested during 2006, 2007 and 2008. The E films were made of EVA and thermoplastic polyurethane for the 2007 and 2008 tests. In addition, each year an EVA film without stabilisers was also tested.

The greenhouse covering films were tested at the experimental farm of the University of Bari (Valenzano, Bari, Italy; $41^{\circ} 05^{\prime} \mathrm{N}$ ) (Figure 1). Each film was exposed to natural outdoor weathering and was used to cover two low tunnels without vegetation: one of the two tunnels was sprayed from inside with the agrochemicals (coded S) while the other one was not sprayed and used as control (coded C). Each low tunnel was $20.0 \mathrm{~m}$ long, $1.0 \mathrm{~m}$ wide and $0.8 \mathrm{~m}$ high, with a North-South orientation. Each year the natural outdoor weathering started in spring and ended in autumn allowing the highest solar irradiation of the films during the warmest period of the year. The first test started on 20/04/2006 and ended on 30/10/2006 after 193 days, the second test started on

Table 1. Stabiliser systems used in the manufacturing of the greenhouse films tested at the University of Bari, Italy.

$\begin{array}{llll}\text { Film code } & \text { Stabilisers } & \text { Thiavine UV filter } & \text { Photoluminescent UV filter }\end{array}$

\begin{tabular}{llll} 
A1 & $X$ & & \\
B1 & & & \\
C1 & & $X$ & $X$ \\
D1 & $X$ & $X$ & \\
\hline A2 & $X$ & & \\
B2 & & $X$ & $X$ \\
\hline C2 & & $X$ & \\
D2 & & & \\
\hline E2 & & $X$ & $X$ \\
A3 & & $X$ & $X$ \\
\hline B3 & & $X$ & $X$ \\
D3 & & $X$ & \\
\hline E3 & & $X$ & \\
\hline
\end{tabular}

HALS, hindered amine light stabilisers; NOR-HALS, aminoether type hindered amine light stabilisers; UV, ultra violet. Letter in the film code indicates the stabiliser system. Number indicates the trial year: 1, 2006; 2, 2007; 3, 2008.

Table 2. Radiometric coefficients of the films tested during the 2006 trial.

\begin{tabular}{|c|c|c|c|c|c|c|}
\hline Film & Exposure time, days & Cumulative solar radiation, $\mathrm{MJ} / \mathrm{m}^{2}$ & Solar trans, \% & PAR trans, $\%$ & UVA trans, \% & LWIR trans, \% \\
\hline Al_0 & 0 & 0 & 89.5 & 89.1 & 80.8 & 62.3 \\
\hline Al_C & 193 & 3360 & 88.6 & 87.3 & 73.9 & 47.5 \\
\hline Al_S & 193 & 3360 & 86.0 & 84.2 & 62.6 & 34.7 \\
\hline B1_0 & 0 & 0 & 88.1 & 88.3 & 45.7 & 59.3 \\
\hline B1_C & 193 & 3360 & 87.6 & 87.1 & 48.8 & 58.1 \\
\hline B1_S & 193 & 3360 & 88.7 & 87.8 & 45.0 & 49.6 \\
\hline Cl_0 & 0 & 0 & 90.2 & 90.1 & 78.6 & 57.3 \\
\hline Cl_C & 193 & 3360 & 88.4 & 87.5 & 77.3 & 56.6 \\
\hline Cl_S & 193 & 3360 & 89.9 & 88.8 & 71.5 & 40.9 \\
\hline D1_0 & 0 & 0 & 90.2 & 91.0 & 37.2 & 57.9 \\
\hline D1_C & 193 & 3360 & 89.2 & 89.2 & 34.5 & 55.6 \\
\hline D1_S & 193 & 3360 & 88.7 & 88.5 & 35.4 & 50.0 \\
\hline
\end{tabular}

PAR, photosynthetically active radiation; UVA, ultraviolet radiation; LWIR, long wave infrared radiation; 0 , new film; C, control film; S, sprayed film; trans, transmissivity. Solar wavelength range, $300-2500 \mathrm{~nm}$; PAR wavelength range, $400-700 \mathrm{~nm}$; UVA wavelength range, $320-380 \mathrm{~nm}$; LWIR wavelength range, 7500-12,500 nm. 
20/04/2007 and ended on 19/10/2007 after 182 days, and the third test started on 29/04/2008 and ended on 4/11/2008 after 189 days.

The greenhouse films were sprayed with a water solution containing agrochemicals based on sulphur, iron and chlorine weekly for six months in each year-test by a system consisting of a pump connected with pipes and nozzles located inside the low tunnels. The choice of iron, chlorine and sulphur was based on a private communication by P.A.T.I. S.p.A. (2006) that made available the results of a survey into the causes of early film failures, including detected contamination as chemical elements and their concentration in the film. The commercially available agrochemicals applied were: i) a foliar fertiliser containing iron with the trade name Sequestrene $®$ Life (Syngenta Crop Protection S.p.A., Milan, Italy); ii) a fungicide containing sulphur with the trade name Tiovit ${ }^{\circledR}$ Jet (Syngenta Crop Protection); iii) a fungicide containing chlorine with the trade name Topas ${ }^{\circledR}$ (Syngenta Crop Protection). The doses of the active principles of the agrochemicals sprayed weekly per square meter of film surface area during the tests were: $3.35 \mathrm{~g} / \mathrm{m}^{2}$ for sulphur; $0.21 \mathrm{~g} / \mathrm{m}^{2}$ for chlorine; $0.26 \mathrm{~g} / \mathrm{m}^{2}$ for iron during $2006 ; 2.00 \mathrm{~g} / \mathrm{m}^{2}$ for sulphur; $0.13 \mathrm{~g} / \mathrm{m}^{2}$ for chlorine; $0.15 \mathrm{~g} / \mathrm{m}^{2}$ for iron during 2007; and $0.500 \mathrm{~g} / \mathrm{m}^{2}$ for sulphur; $0.03 \mathrm{~g} / \mathrm{m}^{2}$ for chlorine; $0.03 \mathrm{~g} / \mathrm{m}^{2}$ for iron during 2008 . The doses of the active principles of the sprayed agrochemicals were modified every year in order to tentatively approach the concentrations of contaminants corresponding to the limits of contamination suggested by CEPLA (2012) and according to the confidential releases by the P.A.T.I. (2006).

Solar radiation hitting the films was measured by a pyranometer (model 8-48, Eppley Laboratory, Newport, RI, USA) in the wavelength range 0.3-3 $\mu \mathrm{m}$. Air temperature inside and outside the tunnels was measured by means of thermistors. Data were recorded every $60 \mathrm{~s}$ by two data loggers (CR 1000 and CR 10X, Campbell, Logan, USA) and stored as $15 \mathrm{~min}$ average values.

Radiometric tests were carried out at the University of Bari by means of two spectrophotometers in order to evaluate the spectral transmissivity of film samples at the beginning and at the end of the trial. Spectral transmissivity $\tau(\lambda)$ of a greenhouse film is the fraction of the incident energy radiant flux that is transmitted at a specific wavelength $\lambda$. Radiometric properties of the covering materials were defined by means of the transmissivity coefficients calculated as average values of the spectral transmissivity over different wavelength bands: the solar wavelength range $(300-2500 \mathrm{~nm})$, the photosynthetically active radiation (PAR) range $(400-700 \mathrm{~nm})$ and the long wave infrared radiation (LWIR) range (7500-12,500 $\mathrm{nm})$.

Spectral direct transmissivity was measured in the solar range, from 200 to $2500 \mathrm{~nm}$, by a double beam UV-VIS-NIR spectrophotometer (Lambda 950, Perkin Elmer Instruments, Norwalk, CT, USA) in steps of $10 \mathrm{~nm}$ using radiation with a direct perpendicular incidence. Spectral total transmissivity was measured by means of an integrating sphere (diameter $60 \mathrm{~mm}$ ) used as receiver of the Lambda 950 spectrophotometer, with a double beam comparative method (Wendlandt and Hecht, 1966). Spectral diffuse transmissivity was calculated by subtracting the direct transmissivity from the total transmissivity. The transmissivity coefficient in the solar range was calculated as the weighted average value of the spectral transmissivity using the spectral distribution of the solar radiation at the ground level as weighting function (Duffie and Beckman, 1991; Papadakis et al., 2000; Vox et al., 2005; Vox and Schettini, 2007; Sica and Picuno, 2008; De Salvador et al., 2008).

Spectral transmissivity in the LWIR range, between 2500 and 25,000 $\mathrm{nm}$, was measured by an FT-IR spectrophotometer (1760 X, PerkinElmer Instruments, Norwalk, CT, USA) in steps of $4 \mathrm{~cm}^{-1}$ using radiation with a direct perpendicular incidence. The transmissivity coefficients in the LWIR range were calculated as average values of the spectral transmissivity in the wavelength range from 7500 to $12,500 \mathrm{~nm}$ (Papadakis et al., 2000; Vox and Schettini, 2007).

\section{Results and discussion}

The radiometric parameters of the films tested, i.e. the total transmissivity coefficients calculated in the solar, in the PAR, in the UVA and in the LWIR wavelength ranges, are shown in Tables 2-4. The radiometric tests were carried out on samples taken at the beginning of each trial for the new films (coded 0 ) and at the end of the trials both for the control films (coded C) subjected only to the natural weathering, and for the sprayed films (coded S) subjected to the natural weathering and to the spray of the agrochemicals. The cumulative solar radiation was calculated from the day of the film installation. In the 2008 trial, the average values of the maximum, minimum and mean daily air temper-

Table 3. Radiometric coefficients of the films tested during the 2007 trial.

\begin{tabular}{|c|c|c|c|c|c|c|}
\hline Film & Exposure time, days & Cumulative solar radiation, $\mathrm{MJ} / \mathrm{m}^{2}$ & Solar trans, $\%$ & PAR trans, $\%$ & UVA trans, $\%$ & LWIR trans, $\%$ \\
\hline A2_0 & 0 & 0 & 94.3 & 94.3 & 91.8 & 62.1 \\
\hline A2_C & 182 & 3614 & 87.0 & 85.8 & 73.7 & 51.7 \\
\hline A2_S & 182 & 3614 & 86.0 & 83.8 & 55.6 & 18.6 \\
\hline B2_0 & 0 & 0 & 91.6 & 92.0 & 56.6 & 58.9 \\
\hline B2_C & 182 & 3614 & 86.8 & 86.0 & 53.3 & 56.5 \\
\hline B2_S & 182 & 3614 & 86.3 & 84.3 & 56.9 & 26.2 \\
\hline C2_0 & 0 & 0 & 94.0 & 94.3 & 81.9 & 57.8 \\
\hline C2_C & 182 & 3614 & 88.1 & 87.3 & 76.4 & 56.4 \\
\hline C2_S & 182 & 3614 & 88.6 & 86.4 & 58.3 & 18.4 \\
\hline D2_0 & 0 & 0 & 93.3 & 94.6 & 37.4 & 56.8 \\
\hline D2_C & 182 & 3614 & 86.7 & 86.4 & 40.6 & 57.3 \\
\hline D2_S & 182 & 3614 & 90.8 & 90.5 & 41.4 & 42.7 \\
\hline E2_0 & 0 & 0 & 91.8 & 92.1 & 63.7 & 30.5 \\
\hline E2_C & 182 & 3614 & 87.3 & 86.4 & 65.4 & 29.9 \\
\hline E2_S & 182 & 3614 & 86.8 & 84.9 & 49.9 & 18.5 \\
\hline
\end{tabular}

PAR, photosynthetically active radiation; UVA, ultraviolet radiation; LWIR, long wave infrared radiation; 0 , new film; C, control film; S, sprayed film; trans, transmissivity. Solar wavelength range, 300-2500 $\mathrm{nm}$; PAR wavelength range, $400-700 \mathrm{~nm}$; UVA wavelength range, $320-380 \mathrm{~nm}$; LWIR wavelength range, 7500-12,500 $\mathrm{nm}$. 
Table 4. Radiometric coefficients of the films tested during the 2008 trial.

\begin{tabular}{|c|c|c|c|c|c|c|}
\hline Film & Exposure time, days & Cumulative solar radiation, $\mathrm{MJ} / \mathrm{m}^{2}$ & Solar trans, $\%$ & PAR trans, $\%$ & UVA trans, $\%$ & LWIR trans, \% \\
\hline A3_0 & 0 & 0 & 90.1 & 89.5 & 78.5 & 57.1 \\
\hline A3_C & 189 & 3529 & 89.8 & 88.4 & 68.5 & 41.4 \\
\hline A3_S & 189 & 3529 & 85.7 & 84.0 & 63.6 & 32.0 \\
\hline B3_0 & 0 & 0 & 86.4 & 86.4 & 36.5 & 39.8 \\
\hline B3_C & 189 & 3529 & 90.4 & 89.9 & 50.9 & 51.8 \\
\hline B3_S & 189 & 3529 & 92.1 & 92.1 & 49.8 & 45.4 \\
\hline D3_0 & 0 & 0 & 82.7 & 81.6 & 16.1 & 34.2 \\
\hline D3_C & 189 & 3529 & 89.2 & 89.1 & 30.6 & 49.0 \\
\hline D3_S & 189 & 3529 & 91.2 & 90.7 & 40.9 & 46.3 \\
\hline E3_0 & 0 & 0 & 92.2 & 92.7 & 62.5 & 30.3 \\
\hline E3_C & 189 & 3529 & 92.7 & 93.0 & 80.1 & 29.6 \\
\hline E3_S & 189 & 3529 & 94.1 & 94.1 & 77.3 & 26.7 \\
\hline
\end{tabular}

PAR, photosynthetically active radiation; UVA, ultraviolet radiation; LWIR, long wave infrared radiation; 0 , new film; C, control film; S, sprayed film; trans, transmissivity. Solar wavelength range, $300-2500 \mathrm{~nm}$; PAR wavelength range, $400-700 \mathrm{~nm}$; UVA wavelength range, $320-380 \mathrm{~nm}$; LWIR wavelength range, $7500-12,500 \mathrm{~nm}$.

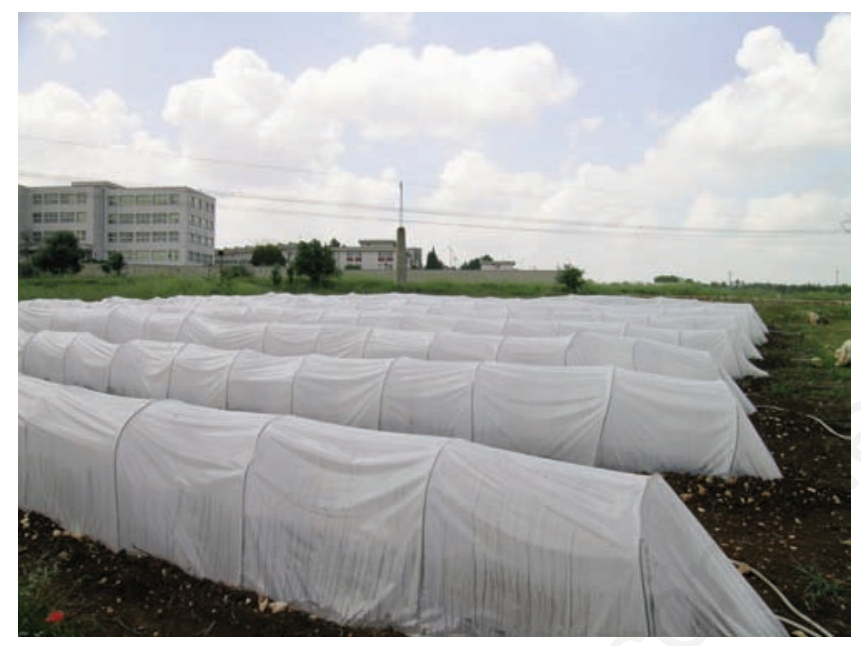

Figure 1. The experimental field at the University of Bari, Italy.

ature were calculated from $30 / 4$ to 30/9. Maximum temperatures were $56.2^{\circ} \mathrm{C}$ for the tunnel covered with B3 film, $55.9^{\circ} \mathrm{C}$ in the tunnel covered with B3_S film, $54.5^{\circ} \mathrm{C}$ in the tunnel covered with A3 film; maximum external air temperature was $32.0^{\circ} \mathrm{C}$. Minimum temperatures were $14.4^{\circ} \mathrm{C}$ for the tunnel covered with $\mathrm{B} 3 \mathrm{film}, 15.5^{\circ} \mathrm{C}$ in the tunnel covered with B3_S film, $14.7^{\circ} \mathrm{C}$ in the tunnel covered with $\mathrm{A} 3 \mathrm{film}$; minimum external air temperature was $16.4^{\circ} \mathrm{C}$. The mean temperature was $32.7^{\circ} \mathrm{C}$ for the tunnel covered with $\mathrm{B} 3 \mathrm{film}, 32.3^{\circ} \mathrm{C}$ in the tunnel covered with B3_S film, $31.8^{\circ} \mathrm{C}$ in the tunnel covered with A3 film; mean external air temperature was $23.6^{\circ} \mathrm{C}$.

Greenhouse covering films must satisfy the UNI EN 13206:2002 standard (UNI, 2002). This establishes that films with a thickness of 100 $\mu \mathrm{m}$ must have a PAR total transmissivity coefficient higher than $85 \%$. The PAR total transmissivity coefficient of the stabilised films ranged from 84.3\% (B2_S) to 94.6\% (D2_0) (Tables 2-4).

In the solar and in the PAR wavelength range, the radiometric properties of all the films varied at most by $10 \%$, while some of the stabilised films showed in the LWIR range higher variations between the values measured at the beginning of the trial and at the end of the trial. The variation in the transmissivity in the LWIR range suggests changes in the chemical structure of the films with a reduction in their mechanical characteristics (Stefani et al., 2008; Vox et al., 2008; Stefani et al., 2011, Schettini and Vox, 2012). The parallel evaluation of the radiometric characteristics and the mechanical properties of the stabilised films showed a relationship between the variation of the radiometric properties in the LWIR range and the changes of the mechanical properties (Stefani et al., 2011).

The radiometric properties of the A films, made with the basic polymers without UV stabilisers recorded a decrease in the transmissivity coefficients after the exposure in the field (Tables 2-4).

Among all the stabilised films tested, as far as LWIR transmissivity coefficient is concerned, the C2_S film showed the highest decrease from the value measured at the beginning of the test (almost 70\%) (Tables 3). A decrease in the LWIR transmissivity reduces LWIR thermal energy losses.

There was no regular variation in the radiometric coefficients of the B, D and E films in the three trials; the values recorded for the control films were often higher than the values measured for the sprayed films (Tables 2-4). In 2008, the solar total transmissivity coefficient and the PAR transmissivity coefficient of the stabilised film aged in the field were higher than the corresponding values measured at the beginning of the test (Table 4). It seems that a considerable reduction in the agrochemicals has improved the solar transmissivity of the films.

\section{Conclusions}

It is well known that greenhouse plastic films exposed to natural weathering and to agrochemicals are subjected to the degradation of their mechanical properties. The research showed that there was no significant change in the radiometric properties of the films in the solar and in the PAR wavelength range during their exposure to climatic agents and to the agrochemicals. The variation in the transmissivity coefficients was at most $10 \%$ within six months of experimental field test. Higher variations between the values measured at the beginning and at the end of the test (up to $70 \%$ of the initial value) were recorded for the radiometric coefficients of the stabilised films in the LWIR wavelength range. 


\section{References}

Briassoulis D. 2005. The effects of tensile stress and the agrochemical Vapam on the ageing of low density polyethylene (LDPE) agricultural films. Part I. Mechanical behaviour. Polym. Degrad. Stabil. 88:489-503.

Briassoulis D., Schettini E. 2003. Analysis and design of low-density polyethylene greenhouse films. Biosyst. Eng. 84:303-14.

CEPLA (Comité Español de Plásticos en Agricultura). 2012. Directriz CEPLA para filmes de cubierta de invernadero. CEPLA, Madrid, España. Available from: http://www.cepla.com

De Salvador F.R., Scarascia Mugnozza G., Vox G., Schettini E., Mastrorilli M., Bou Jaoudé M. 2008. Innovative photoselective and photoluminescent plastic films for protected cultivation. Acta Hort. 801:115-22.

Desriac P. 1991. The effect of pesticides on the life of greenhouse films. Plasticulture 89:9-16.

Dilara P.A., Briassoulis D. 1998. Standard testing methods for mechanical properties and degradation of low density polytehylene (LDPE) films used as greenhouse covering materials: a critical evaluation. Polym. Test. 17:549-85.

Dilara P.A., Briassoulis D. 2000. Degradation and stabilization of Lowdensity Polyethylene films used as greenhouse covering materials. J. Agric. Eng. Res. 76:309-21.

Duffie J.A., Beckman W.A. 1991. Solar engineering of thermal processes. John Wiley \& Sons, New York, NY, USA.

Espí E., Salmerón A., Fontecha A., García Y., Real A.I. 2007. The effect of different variables on the accelerated and natural weathering of agricultural films. Polym. Degrad. Stabil. 92:2150-4.

Khan J.H., Hamid S.H. 1995. Durability of HALS-stabilized polyethylene film in a greenhouse environment. Polym. Degrad. Stabil. 48:13742.

Kittas C., Baille A. 1998 Determination of the spectral properties of several greenhouse cover materials and evaluation of specific parameters related to plant response. J. Agr. Eng. Res. 71:193-202

Martin-Closas L., Pelacho A.M., Picuno P., Rodríguez D. 2008. Properties of new biodegradable plastics for mulching, and characterization of their degradation in the laboratory and in the field. Acta Hort. 801:275-82.

Nijskens J., Deltour J., Albrecht E., Grataud J., Feuilloley P. 1990. Comparative studies on the ageing of polyethylene film in the laboratory and in practical use. Plasticulture 87:11-20.
Papadakis G., Briassoulis D., Scarascia Mugnozza G., Vox G., Feuilloley P., Stoffers, J.A. 2000. Radiometric and thermal properties of, and testing methods for, greenhouse covering materials. J. Agr. Eng. Res. 77:7-38.

Ruiz P., Pagani F., Vulic I., Lobo F. 2006. Is the service life of greenhouse covers determined by exposure to the sun or by contact with agrochemical substances? Plasticulture 125:37-49.

Rull F., Marin A. 2006. The influence of metham-sodium on the degradation of films used as covers in greenhouse. Plasticulture 126:719.

Sanchez-Lopez S., Prado H.L., Ramirez E., Mendoza N. 1991. Recycling of waste agricultural polyethylene film. Plasticulture 92:49-53.

Schettini E., Vox G. 2012. Effects of agrochemicals on the radiometric properties of different anti-UV stabilized EVA plastic films. Acta Hort. 956:515-22.

Sica C., Picuno P. 2008. Spectro-radiometrical characterization of plastic nets for protected cultivation. Acta Hort 801:245-52.

Stefani L., Schettini E., Vox G. 2011. Correlation between agrochemicals, solar radiation and mechanical properties of greenhouse plastic films. Acta Hort. 893:281-8.

Stefani L., Zanon M., Modesti M., Ugel E., Vox G., Schettini E. 2008. Reduction of the environmental impact of plastic films for greenhouse covering by using fluoropolymeric materials. Acta Hort. $801: 131-8$.

UNI (Ente Nazionale Italiano di Unificazione). 2002. Covering thermoplastic films for use in agriculture and horticulture. UNI EN 13206:2002. Available from: http://www.uni.com/

Vox G., Schettini E. 2007. Evaluation of the radiometric properties of starch-based biodegradable films for crop protection. Polym. Test. 26:639-51.

Vox G., Schettini E., Scarascia Mugnozza G. 2005. Radiometric properties of biodegradable films for horticultural protected cultivation. Acta Hort. 691:575-82.

Vox G., Schettini E., Stefani L., Modesti M., Ugel E. 2008. Effects of agrochemicals on the mechanical properties of plastic films for greenhouse covering. Acta Hort. 801:155-62.

Vox G., Teitel M., Pardossi A., Minuto A., Tinivella F., Schettini E. 2010. Sustainable greenhouse systems. In: A. Salazar and I. Rios (eds.) Sustainable agriculture: technology, planning and management. Nova Science Publishers, Inc., New York, NY, USA, pp 1-79.

Wendlandt W.W., Hecht H.G. 1966. Reflectance spectroscopy. John Wiley and Sons, New York, NY, USA, pp 253-274. 